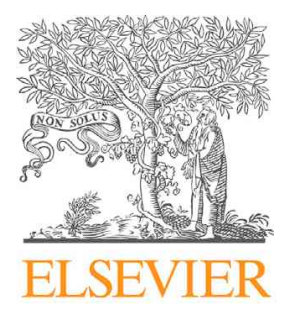

aDepartment of Paediatric Urology, Royal Manchester Children's Hospital, UK

bepartment of Paediatric Surgery, Royal Manchester Children's Hospital, UK

'Institute for Surgical Research, University of Szeged, Hungary

Correspondence to:

T. Cserni, Department of Paediatric Urology, Royal Manchester Children's Hospital, Oxford Road, Manchester, M13 9WL, UK, Tel.: +44 1612761234; fax: +44 161701 2928

tcserni@yahoo.com (T. Cserni)

raimondo.cervellione@cmft.nhs.uk

(R.M. Cervellione)

hajnalid1987@hotmail.com

(D. Hajnal)

gvarga36@gmail.com

(G. Varga)

rainerkubiak@hotmail.com

(R. Kubiak)

george.rakoczy@cmft.nhs.uk (G. Rakoczy)

kaszaki.jozsef@med.u-szeged.hu (J. Kaszaki)

boros.mihaly@med.u-szeged.hu (M. Boros)

anju.goyal@cmft.nhs.uk

(A. Goyal)

alan.dickson@cmft.nhs.uk

(A. Dickson)

\section{Keywords}

Clam ileocystoplasty; Short mesentery; Intramural ileal blood supply

Received 17 June 2014 Accepted 7 October 2014 Available online 20 February 2015

\title{
Alternative ileal flap for bladder augmentation if mesentery is short
}

\author{
T. Cserni ${ }^{a, c, 1}$, R.M. Cervellione ${ }^{a, c}$, D. Hajnal ${ }^{c}$, G. Varga ${ }^{c}$, \\ R. Kubiak ${ }^{b}$, G. Rakoczy ${ }^{b}$, J. Kaszaki ${ }^{c}, M$. Boros $^{c}$, A. Goyal ${ }^{a}$, \\ A. Dickson ${ }^{a}$
}

\section{Summary}

\section{Purpose}

To date the clam ileocystoplasty is the preferred method of bladder augmentation in children when the urodynamic problem is non-compliance and/or detrusor overactivity. The key to this technique is the incision of the bladder wall deep into the pelvis down to the trigone in order to avoid a diverticulum like neobladder and to provide adequate margin for augmentation. The detubularised ileum flap therefore has to reach to the bottom of the divided bladder on a reliable vascular pedicle without significant tension. A short ileal mesentery caused by previous surgery, peritonitis, peritoneal dialysis or ventriculo-peritoneal shunt may complicate surgery and compromise outcome.

We hypothesized we can rely on the communication of the intramural vessels within the intestine and can detubularise the ileum adjacent to the mesentery rather than along the antimesenteric line and this could be combined with ligation of some vasa recta (VR) in order to create alternative ileum flaps, which reach further into the pelvis.

Our aim was to assess the viability of the alternative flaps detubularised along the paramesenteric line and measure how many VR could be sacrificed beyond the tertiary arcades.

\section{Materials and methods}

After ethical approval adjacent ileal segments were detubulirased along the antimesenteric line (Group 1) and along the paramesenteric line (Group 2) in 5 minipigs in general anaesthesia. Ligation of $0,1,2,3$ and 4 VR has been performed starting from the free end of the segments. The length of the ileal flaps was recorded. The microcirculation of flap edges was detected by in vivo microscopy using orthogonal polarising spectral imaging (Cytoscan A/R Cytometrics, PA, USA). Clam ileocystoplasty was performed with the ileum detubularised along the paramesenteric line without ligation of VR. Specimens of the augmented bladder were obtained after 4 weeks and stained with Hematoxilin + Eosin.

Results

No alteration in capillary red blood cell velocity (RBCV) and perfusion rate (PR) was observed after paramesenteric detubularisation. The flaps in Group 2 reached $20.25 \pm 0.5 \mathrm{~mm}$ longer vs. control. This is $98 \%$ of the mean bowel width $(20.5 \pm 0.57 \mathrm{~mm})$ measured in the animals. Ligation of each VR further increased the length of both flaps (mean:

$10.59 \pm 3.18 \mathrm{~mm}$ ) however ligation of more than 2 VR gradually decreased the microcirculation in both groups. All animals augmented with alternative flap survived, there was no urine leak or suture break down. Histology confirmed viable bowel flaps.

\section{Conclusion}

Paramesenteric detubularisation of the ileum is fully tolerated and results in longer reaching ileal flap vs. control. Only limited ligation of VR is tolerated.

\section{Discussion}

This study showed the first time that clam ileocystoplasty is feasible with ileal flap detubularised along the paramesenteric line. The use of the animal model and the relative short postoperative observation are the main limitations of this study.

\footnotetext{
${ }^{1} 6720$ Szeged, Szőkefalvi-Nagy Béla u. 6, Hungary. Tel.: +36 62545 103; fax: +36 62545743 . 


\section{Introduction}

Due to its good compliance, redundancy, relative low mucus secretion, and less-severe associated metabolic disturbances, the detubularised ileum is the preferred intestinal segment for bladder augmentation [1]. The clam ileocystoplasty is a well-established and popular technique for bladder augmentation in childhood when the urodynamic problem is non-compliance and/or detrusor over activity [2]. The key to this technique is the incision of the non-compliant bladder wall deep into the pelvis down to the trigone, in order to avoid a diverticulum-like neobladder and to provide an adequate margin for augmentation. Therefore, the detubularised ileum flap has to reach to the bottom of the divided bladder on a reliable vascular pedicle, without significant tension. Usually, vessels at the level of the primary, secondary and the tertiary arcades of the mesentery are dissected to create an adequate, long pedicle for the ileum flap (T-shaping). However, it may be difficult to gain enough length in patients with a shortened mesentery caused by previous surgery, peritonitis, peritoneal dialysis or ventriculo-peritoneal shunt $[1,3]$. A sigmoid colon cystoplasty may be an alternative [4]; however, others prefer the small bowel as it may have less mucus secretion and better compliance [2].

Several techniques have been described for lengthening the small bowel mesentery, not only in reconstructive urology but also in restorative proctocolectomy with ileal pouch, anal anastomosis in ulcerative colitis or familial adenomatous polyposis. These techniques usually involve meticulous dissection, selective division of mesenteric blood vessels, 'stepladder incision' of the mesenteric peritoneum [5,6] and vein grafting of the superior mesenteric artery [7].

The present study investigated other options to create alternative ileum flaps that reach further into the pelvis.
It was hypothesised that the antimesenteric intramural communication of the vasa recta (VR) within the intestine, as observed by anatomists [8-10], can be relied on, and that the ileum adjacent to the mesentery rather than along the antimesenteric line can be detubularised without compromising the microcirculation. Monti (1997) and Casale (1999) also found that a short ileal segment detubularised paramesenterically remained viable and could be used for a continent urinary stoma for intermittent catheterisation [11,12]. Ileum detubularised along a paramesenteric line will result in alternative ileal flaps reaching deeper into the pelvis (Fig. 1).

During T-shaping, usually, no vessels are dissected beyond the level of the tertiary arcades, but ligation of a few VR should give more length to the flap. Neighbouring VR have been reported to have communicating anastomoses, and ligation of some vessels may therefore not compromise microcirculation of the adjacent bowel segment $[9,10]$.

The aim of the present study was to assess the viability and safety of the alternative flaps that were detubularised along the paramesenteric line, and to measure how many VR could be sacrificed beyond the tertiary arcades.

\section{Materials and methods}

\section{Animals, instrumentation and surgery}

Inbred, female Vietnamese mini pigs ( $n=5$; weight 25-30 kg) were fasted for $36 \mathrm{~h}$ prior to surgery, but received water ad libitum. Anaesthesia was induced with an intramuscular injection of ketamine $(20 \mathrm{mg} / \mathrm{kg})$ and xylazine $(2 \mathrm{mg} / \mathrm{kg})$, and maintained with a continuous infusion of propofol $(2 \% ; 50 \mu \mathrm{l} / \mathrm{kg} / \mathrm{min}$ IV). Endotracheal intubation and mechanical volume-controlled ventilation

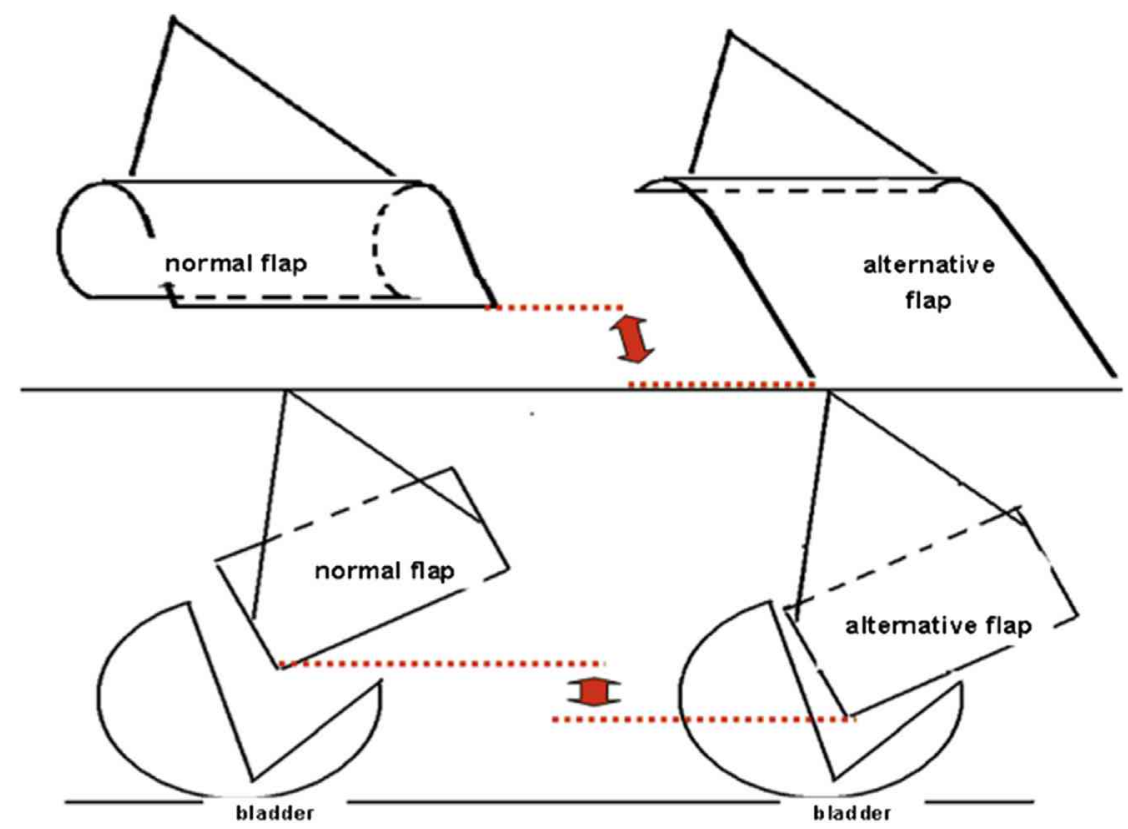

Figure 1 The paramesenteric (alternative) detubularised ileal flap reaches further vs the (antimesenterically detubularised) normal flap. 
was used. Norocarp S (carprofen; $4 \mathrm{mg} / \mathrm{kg}$ ) and normal saline infusion were administered via a cannulated ear vein.

The animals were placed in a supine position on a heating pad and a midline laparotomy was performed. Adjacent ileal segments were isolated. In the control group, the ileum was detubularised along the antimesenteric line. In the alternative flap $(A D)$ group, the ileum was detubularised along the paramesenteric line. Subsequent ligation and dissection of $0,1,2,3$ and 4 VR was performed in both groups, starting from the free end of the segments. The lengths of the flaps were measured from a point marked with a suture on the base of the mesentery, and the differences between the two groups were recorded (Fig. 2). Intravital videomicroscopy was performed to examine the microcirculation of the flaps' mucosa. At the end of the measurements, the flaps were removed and the new, $20 \mathrm{~cm}$ long ileum was isolated for the clam ileocystoplasty.

After recovery, all animals were kept on water for $24 \mathrm{~h}$, and liquid food was then available for $48-72 \mathrm{~h}$; after which, they fed normally. Analgesia (carprofen) and antibiotics (enrofloxacin) were continued for three days postoperatively.

After four weeks, the animals were anaesthetised again, and the augmented bladders were examined and removed. Specimens containing the distal suture line with the bladder and the ileal flap were harvested. Conventional Haematoxylin and Eosin staining, and light microscopy examination were performed.

\section{Intravital videomicroscopy of the microcirculation}

The intravital orthogonal polarisation spectral (OPS) imaging technique (Cytoscan A/R, Cytometrics, PA, USA) was used for visualising the microcirculation of the flaps' mucosa. The OPS technique utilises reflected, polarised light at the wavelength of the isobestic point of oxyhaemoglobin and deoxyhaemoglobin $(548 \mathrm{~nm})$. As polarisation is

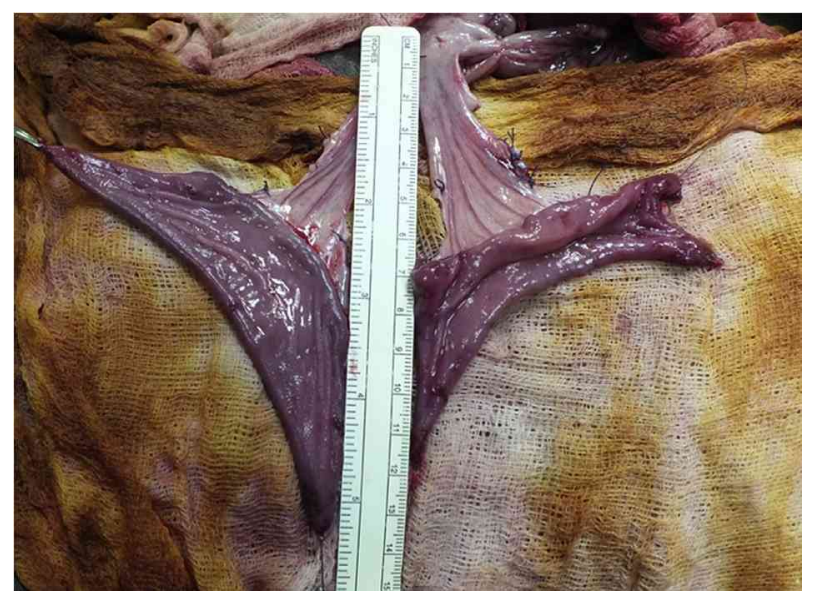

Figure 2 Left: paramesenteric (alternative) detubularised ileal flap. Right: (antimesenterically detubularised) normal flap. Note that the alternative flap reaches further. Vasa recta were divided and ligated at the ends of the segment where the mesentery meets the bowel. The mesentery with the ligatures retracted higher up. preserved in reflection, only photons scattered from a depth of $2-300 \mu \mathrm{m}$ contribute to image formation. A $10 \times$ objective was placed onto the serosal surface of the ascending colon, and microscopic images were recorded with an S-VHS video recorder 1 (Panasonic AG-TL 700, Japan). Quantitative assessment of the microcirculatory parameters was performed off-line by frame-to-frame analysis of the videotaped images. Red blood cell velocity (RBCV) $(\mu \mathrm{m} / \mathrm{s})$ changes and perfusion rates (PR) (\%) in the intestinal villi were determined in three separate fields by means of a computer-assisted image analysis system (IVM Pictron, Budapest, Hungary) $[13,14]$. One investigator performed all microcirculatory evaluations.

\section{The clam ileocystoplasty}

The ileum segment was detubularised along the paramesenteric line on the posterior wall, and the continuity of the ileum was then restored with a single layer anastomosis. The bladder was incised down to the trigone and the ileum flap was sutured to the bladder using $5 / 0$ Vicryl; $12 \mathrm{~F}$ Malecot catheters were placed urethrally.

\section{Histopathological analysis}

For each animal, full-thickness tissue biopsies that were taken from the bowel-bladder junction on week 4 after surgery were analysed. The tissues were fixed in $6 \%$ buffered formalin, embedded in paraffin, cut into $4-\mu \mathrm{m}$-thick sections and stained with Haematoxylin and Eosin.

\section{Statistical analysis}

Data analysis was performed with a statistical software package (SigmaStat for Windows; Jandel Scientific, Germany). Friedman repeated measures of analysis of variance on ranks and Mann-Whitney Test were applied within groups. In the Figures, median values, 75th and 25th percentiles are given; $P$-values $<0.05$ were considered to be significant.

\section{Results}

\section{Flap length}

Paramesenteric detubularisation of the ileum resulted in a mean $20.25 \pm 0.5 \mathrm{~mm}$ longer flap vs detubularisation along the mesenteric line. The difference in length reached $98 \%$ of the mean bowel width $(20.5 \pm 0.57 \mathrm{~mm})$ measured in the animals. Ligation of each VR further increased the length of both flaps. The length gain was different after each vessel: mean, $9.84 \mathrm{~mm}$; range, $7-17 \mathrm{~mm}$ (all data are summarised in Table 1).

\section{Microcirculation}

The statistical analysis did not show significant difference in the RBCV and PR between the antimeseterically detubularised ileal flaps and the paramesenterical detubularised flaps. Ligation of the VR up to one vessel did not 
Table 1 Length, capillary red blood cell velocity (RBCV) and perfusion rate (PR) of control and alternative ileum flap after ligation of vasa recta.

\begin{tabular}{|c|c|c|c|c|c|c|}
\hline \multicolumn{2}{|c|}{ Diameter of the bowel $(\mathrm{mm})$} & \multicolumn{5}{|l|}{$20.5 \pm 0.57$} \\
\hline \multicolumn{2}{|c|}{ Number of ligated vessels } & 0 & 1 & 2 & 3 & 4 \\
\hline \multirow{7}{*}{$\begin{array}{l}\text { Control } \\
\text { ileum flap }\end{array}$} & $\operatorname{RBCV}\left(\mu \mathrm{m} \mathrm{s}^{-1}\right)$ & Median: 564.820 & Median:432.123 & Median:379.279* & Median:274.720* & Median: 174.278 \\
\hline & & $25 \%: 521.250$ & $25 \%: 396.510$ & $25 \%: 360.311$ & $25 \%: 234.958$ & $25 \%: 115.194$ \\
\hline & & $75 \%: 594.357$ & $75 \%: 467.285$ & $75 \%: 399.400$ & $75 \%: 290.250$ & $75 \%: 208.297$ \\
\hline & PR (\%) & Median: 1.000 & Median: 1.000 & Median: $0.778^{*}$ & Median: $0.669^{*}$ & Median: $0.440^{*}$ \\
\hline & & $25 \%: 0.995$ & $25 \%: 0.975$ & $25 \%: 0.694$ & $25 \%: 0.658$ & $25 \%: 0.351$ \\
\hline & & $75 \%: 1.000$ & $75 \%: 1.000$ & $75 \%: 0.930$ & $75 \%: 0.688$ & $75 \%: 0.507$ \\
\hline & Length (mm) & 0 & $17.75 \pm 2.21$ & $28.75 \pm 7.58$ & $38.5 \pm 9.6$ & $45.5 \pm 9.25$ \\
\hline \multirow{7}{*}{$\begin{array}{l}\text { Alternative } \\
\text { ileum flap }\end{array}$} & $\operatorname{RBCV}\left(\mu \mathrm{m} \mathrm{s} \mathrm{s}^{-1}\right)$ & Median: 584.238 & Median: 392.895 & Median: $264.854^{*}$ & Median: $176.225^{*}$ & Median: 65.658 \\
\hline & & $25 \%: 549.072$ & $25 \%: 353.378$ & $25 \%: 252.373$ & $25 \%: 166.033$ & $25 \%: 40.326$ \\
\hline & & $75 \%: 625.915$ & $75 \%: 415.365$ & $75 \%: 287.159$ & $75 \%: 185.324$ & $75 \%: 80.235$ \\
\hline & PR (\%) & Median: 1.000 & Median: 0.994 & Median: 0.901 & Median: $0.650^{*}$ & Median: $0.299^{*}$ \\
\hline & & $25 \%: 0.995$ & $25 \%: 0.956$ & $25 \%: 0.821$ & 25\%: 0.499 & $25 \%: 0.184$ \\
\hline & & $75 \%: 1.005$ & $75 \%: 1.000$ & $75 \%: 0.935$ & $75 \%: 0.671$ & $75 \%: 0.357$ \\
\hline & Length (mm) & $20.25 \pm 0.5$ & $30.75 \pm 9.74$ & $39.75 \pm 11.98$ & $48.5 \pm 13.02$ & $59.5 \pm 11.67$ \\
\hline
\end{tabular}

" $p<0.05$ within group and baseline value.

affect RBCV and PR, compared to the baseline values in both groups. Ligation of 2, 3 and 4 vessels gradually decreased RBCV and PR in both groups significantly; however, after ligation of the 4th vessel, marked circulation was still seen (Fig. 3, Fig. 4).

\section{Bladder augmentation}

All animals recovered after the clam ileocystoplasty performed with a paramesenterically detubularised ileum flap.
There was no urine leakage or suture break down found at the autopsy.

\section{Histology}

The Hematoxylin and Eosin staining confirmed that viable bowel flaps had anastomosed to the bladder. The bowel mucosa was not atrophic, and no fibrosis was seen in the bowel flap.
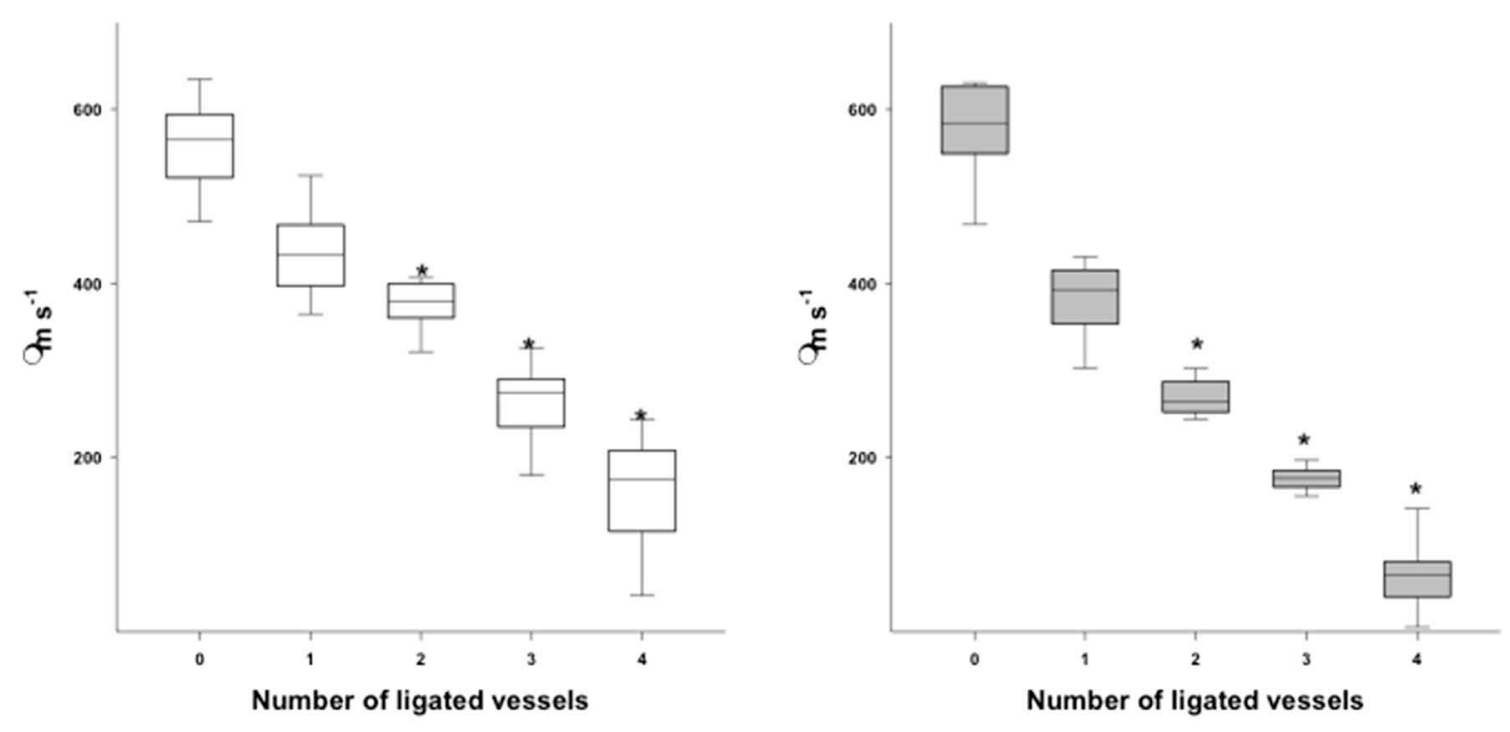

${ }^{*} \mathrm{p}<0.05$ within group and baseline value (Friedman Repeated Measures Analysis)

Figure 3 Changes in red blood cell velocity in the normal and the alternative flap: the plots demonstrate the median values and the 25th (lower whisker) and 75th (upper whisker) percentiles. ${ }^{*} P<0.05$ within groups vs baseline values. 

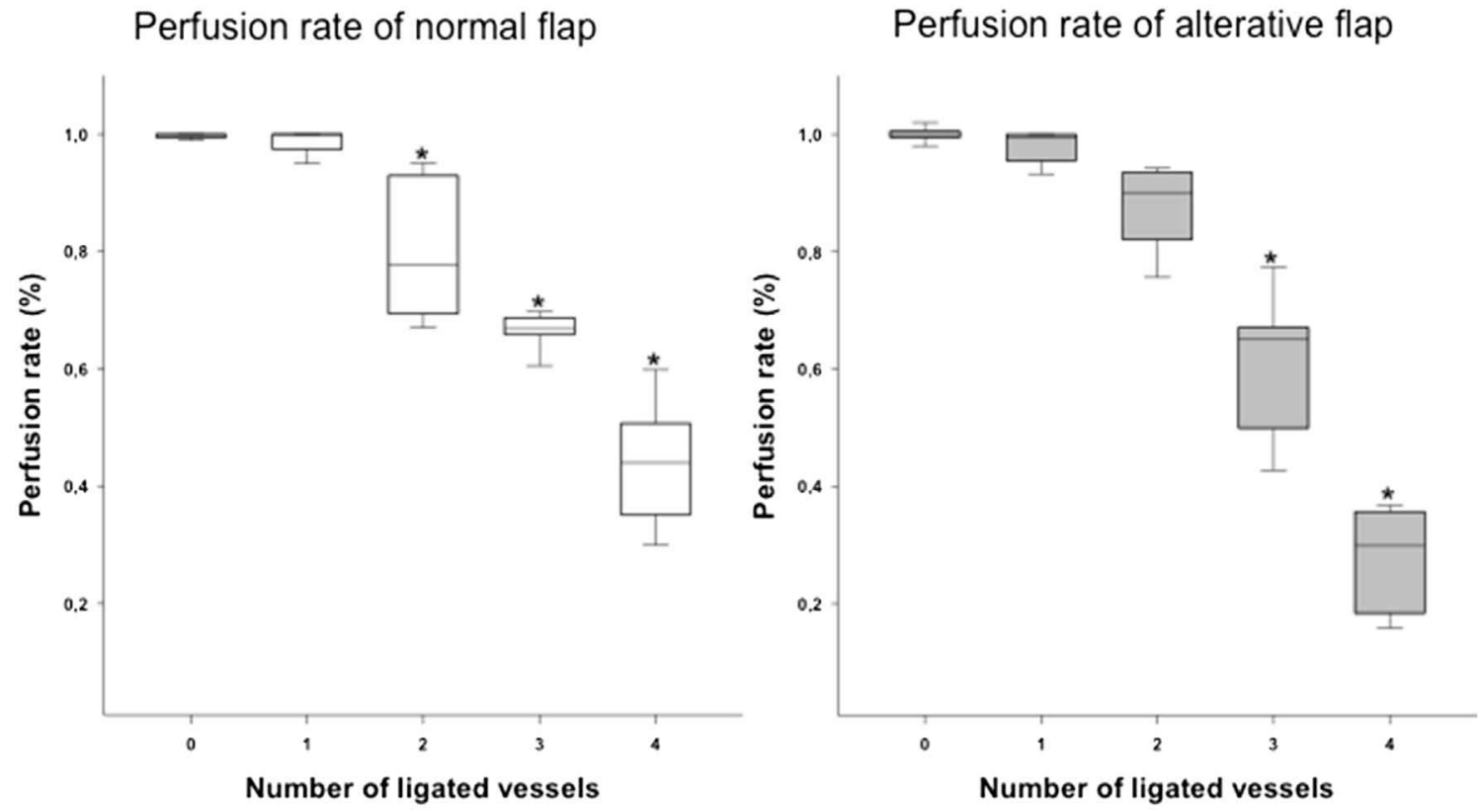

${ }^{*} \mathrm{p}<0.05$ within group and baseline value (Friedman Repeated Measures Analysis)

Figure 4 Changes in perfusion rate in the normal and the alternative flap: the plots demonstrate the median values and the 25th (lower whisker) and 75th (upper whisker) percentiles. ${ }^{*} P<0.05$ within groups vs baseline values.

\section{Discussion}

When bowel segments are used in reconstructive urological procedures, tension-free bowel anastomosis and wellperfused tissue are essential. A short mesentery, due to previous surgeries, peritonitis, peritoneal dialysis and VP shunt, may complicate these procedures [1]. Levin used the 'stepladder incision' technique and gained up to $30 \mathrm{~mm}$ of additional length for urological reconstruction, without complications [5]. According to the Gray's Anatomy [15], this is $80 \%$ of the diameter of an adult human ileum (37.5 mm).

In the pigs, the paramesenteric detubularisation of the ileum resulted in $20.25 \pm 0.5 \mathrm{~mm}$-longer alternative flaps; this reached $98 \%$ of the diameter of the bowel $(20.5 \pm 0.57 \mathrm{~mm})$. These results suggest that paramesenteric detubularisation is more effective than Levin's procedure. Further benefit could be achieved if both techniques were combined.

Intravital microscopy showed no significant difference in the velocity of the circulating erythrocytes and the perfusion rate at the edge of the alternative ileal flaps. All five animals survived the operation without suture breakdown or urine leakage, and the histology did not reveal necrosis at the anastomosis line. These findings demonstrate that paramesenteric detubularisation is safe and does not compromise the microcirculation of the ileum and wound healing.

According to the observation of Eisberg and Noer $[9,10]$ it was expected that ligation of some VR may not alter microcirculation. Ligation of one VR did not alter the RBCV and PR significantly, either in the control or in the alternative flap (AD) groups. This may suggest that paramesenteric detubularisation and ligation of one VR could be combined to gain more length. In clinical practice, however, due to the possible anatomical variations, it could be difficult to assess the limitation of the VR ligation unless precise intraoperative intravital microscopy is performed; therefore, this is not suggested.

Although there are no exact data available in the literature regarding the values of $R B C V$ and PR required for uneventful wound healing, in the present study, it was hypothesised that any compromise in the microcirculation may result in complications.

In summary, paramesenteric detubularisation of the ileum results in significantly longer ileal flaps for clam ileocystoplasty. This technique does not disturb the microcirculation of the ileal flap and has been proven to be safe in animal models. The paramesenteric detubularisation can be used as an addition to the present techniques of mesenteric lengthening like T-shaping and 'stepladder incision' of the mesenteric peritoneum. Tolerance of VR ligation is limited; therefore, it is not suggested in clinical practice.

\section{Conflict of interest statement}

The authors disclose no conflict of interest.

\section{Ethical approval}

The experiments were carried out in strict adherence to the National Institute of Health guidelines for the use of experimental animals. The study was approved by the Ethical Committee for the Protection of Animals in 
Scientific Research at the University of Szeged (Permission no: V./1637/2013.).

\section{Acknowledgements}

The present study was partially supported by the Charitable Found Manchester. The sponsors were not involved in: the study design, collection, analysis and interpretation of data; the writing of the manuscript; and the decision to submit the manuscript for publication.

\section{References}

[1] Adams MC, Joseph BD. Augmentation cystoplasty, urinary tract reconstruction in children. In: Campbell-Walsh urology. 10th ed. Philadelphia: Elsevier; 2012. p. 3672.

[2] Steinbrecher HA, Malone PS, Rickwood AMK. Surgery for impaired/high-pressure bladder capacity. In: Thomas DFM, Duffy GP, Rickwood AMK, editors. Essentials of paediatric urology. London: Informa Healthcare; 2008. p. 180.

[3] Sigaroudinia MO, Baillie C, Ahmed S, Mallucci C. Sclerosing encapsulating peritonitis-a rare complication of ventriculoperitoneal shunts. J Pediatr Surg 2008;43:31-3.

[4] Arlen AM, Merriman LS, Elmore JM, Smith EA, Kirsch AJ. Rapid construction of sigmoid bladder augmentation using absorbable staples: longterm results and comparison to standard colocystoplasty in children with neurogenic bladder. J Pediatr Urol 2014;10:284-8.

[5] Levine LA. Stepladder incision technique for lengthening of bowel mesentery. J Urol 1992;148:351-2.

[6] Baig MK, Weiss EG, Nogueras JJ, Wexner SD. Lengthening of small bowel mesentery: stepladder incision technique. Am J Surg 2006;191:715-7.

[7] Metcalf DR, Nivatvongs S, Sullivan TM, Suwanthanma W. A technique of extending small-bowel mesentery for ileal pouch-anal anastomosis: report of a case. Dis Colon Rectum 2008;51:363-4.

[8] Doran FS. Intramural blood supply of the upper jejunum in man. J Anat 1950;84:283-6.

[9] Eisberg HB. Intestinal arteries. Anat Rec 1924;28:227-42.

[10] Noer RJ. The blood vessels of the jejunum and ileum: a comparative study of man and certain laboratory animals. Am J Anat 1943;73:293-334.

[11] Monti PR, Lara RC, Dutra MA, de Carvalho JR. New techniques for construction of efferent conduits based on the Mitrofanoff principle. Urology 1997;49:112-5.

[12] Casale AJ. A long continent ileovesicostomy using a single piece of bowel. J Urol 1999;162:1743-5.

[13] Cerný V, Turek Z, Parízková R. Orthogonal polarization spectral imaging. Physiol Res 2007;56:141-7.

[14] Vajda K, Szabó A, Kucsa K, Suki B, Boros M. Microcirculatory heterogeneity in the rat small intestine during compromised flow conditions. Microcirculation 2004;11:307-15.

[15] http://www.bartleby.com/107/248.html [accessed 08.03.2015]. 